3 Борисов А.Н. Комментарий к Федеральному закону "Об акционерных обществах". - М.: Дело, 2018. - $632 \mathrm{c}$.

4 Осипенко О.В. Актуальные проблемы инструментов корпоративного управления и акционерного права. - М.: Статут, 2018 - Режим доступа: http://www.consultant.ru/ (дата обращения: 03.03.2020).

${ }^{5}$ Белаш Е.А. Некоторые проблемы защиты прав акционеров на управление акционерным обществом. - Режим доступа: http://www.dnevniknauki.ru/ (дата обращения: 05.03.2020).

\title{
WAYS TO PROTECT THE RIGHTS OF SHAREHOLDERS TO MANAGE THE AFFAIRS OF A JOINT-STOCK COMPANY
}

\author{
(C) 2020 Devyatkina Anna Yuryevna \\ Undergraduate \\ Samara State University of Economics \\ E-mail: anna.devyatkina.1997@mail.ru
}

Keywords: shareholder, shareholder rights, management of a joint-stock company, decision of the General meeting, protection of shareholders ' rights, voting shares, methods of protection of rights, authorized body, extraordinary General meeting of shareholders, corporate law.

The article is devoted to the study of the current state and legal regulation of the Institute for the protection of shareholders ' rights to manage a joint-stock company. The relevance of this topic is due to the development of business relations. The article analyzes these rights and ways to protect them, and also notes the need to make changes to the legislation that regulates ways to protect the right to participate in the management of a joint-stock company, in particular articles 49, 53, 55 of the Federal law "on joint-stock companies". The study of current aspects of management of joint-stock companies will help to better protect the rights of shareholders to manage the Affairs of the joint-stock company.

УДК 347

Код РИНЦ 10.00.00

\section{РОБОТИЗИРОВАННЫЕ ТЕХНОЛОГИИ ИСКУССТВЕННОГО ИНТЕЛЛЕКТА В АСПЕКТЕ ПРАВОВОГО РЕГУЛИРОВАНИЯ}

\author{
() 2020 Дельцова Наталья Вячеславовна \\ кандидат юридических наук, доцент \\ Самарский государственный экономический университет \\ E-mail: natdel@mail.ru
}

Ключевые слова: искусственный интеллект, роботизированная система, правовое регулирование, информационные технологии.

Статья посвящена формированию правового регулирования технологий искусственного интеллекта и роботов в Российской Федерации. Рассматриваются имеющиеся действующие норма- 
тивные акты в данной сфере и проектное законодательство. Представлены предложения по изменению законодательства.

Термин "искусственный интеллект" был предложен в 1956 г. Д. Маккарти на конференции, проводимой в Дартмуте, посвященной исследованию вопросов проявления различных вычислительных способностей разума и созданию интеллектуальных алгоритмов и систем, способных самостоятельно решать поставленные перед ними задачи, принимать решения. Данный термин был положен в основу целого направления научных исследований, направленных на разработку и внедрение компьютерных и других информационных технологий, связанных с человеческим интеллектом, способных к рассуждению, обучению и решению проблем.

До настоящего времени ни один законодательный акт в РФ не содержит определение искусственного интеллекта. Отдельные элементы регулирования присутствуют лишь в документах стратегического и отраслевого характера. В отраслевом документе - ГОСТ P 43.0.5-2009. Национальный стандарт Российской Федерации. "Информационное обеспечение техники и операторской деятельности. Процессы информационно-обменные в технической деятельности. Общие положения", утвержденном Приказом Ростехрегулирования от 15.12.2009 № 959-ст1, искусственный интеллект определяется как моделируемая (искусственно воспроизводимая) интеллектуальная деятельность мышления человека.

Развитее искусственного интеллекта в качестве основного направления развития информационных и коммуникационных технологий упоминается в Указе Президента РФ от 09.05.2017 № 203 "О Стратегии развития информационного общества в Российской Федерации на 2017 - 2030 годы"2, Указе Президента РФ от 01.12.2016 № 642 "О Стратегии научно-технологического развития Российской Федерации"з и др.

Изложенное позволяет сделать вывод о том, что под искусственным интеллектом действующее законодательство понимает информационную технологию, которая содержит элементы (алгоритмы), моделирующие мыслительную (интеллектуальную) деятельность человека.

Представление об искусственном интеллекте, как об информационной технологии позволяет распространять на данное правовое явление нормы Федерального закона "Об информации, информационных технологиях и защите информации" от 27.07.2006 г. № 149-Ф34.

Наряду с понятием "искусственный интеллект" достаточно часто встречается термин "робот". Исследование данной категории осуществляется в аспекте развития робототехники и применении ее результатов в различных отраслях. В данной сфере также действал отраслевой документ - ГОСТ ИСО 8373-2014. "Роботы и робототехнические устройства. Термины и определения"5, который определял, что "робот - приводной механизм, программируемый по двум и более осям, имеющий некоторую степень автономности, движущийся внутри своей рабочей среды и выполняющий задачи по предназначению".

Для целей регулирования в области робототехники указанный документ уазывал виды роботов с учетом предназначения. В приведенном стандарте было представлено понятие разумный робот и робот с элементами искусственного интеллекта, то есть выполняющий работу путем считывания данных из окружающей среды, взаимодействия с внешними источниками и адаптации своего поведения. В настоящее время указанный стандарт 
утрали силу, а новый стандарт, согласно Приказу Росстандарта от 01.11.2019 № 2612 "Об утверждении Программы национальной стандартизации на 2020 год"6 еще не разработан.

Современные исследования в области правового регулирования робототехники уделяют особое внимание именно данной категории роботов ${ }^{7}$. Следует отметить, что Российская Федерация несколько позже, по сравнению с другими государствами, включилась в процесс формирования цифровой экономики, предполагающей активное использование технологий искусственного интеллекта и умных роботов.

В некоторых государствах этот процесс начался гораздо раньше, что нашло отражение во внутригосударственных законодательных актах. Так, например, в Южной Корее еще в 2008 г. был принят Закон о содействии развитию и распространению умных роботов8, в Эстонии в 2017 г. был принят Закон о роботах-курьерах9.

В России на современном этапе можно отметить появление специальных правовых норм на уровне федеральных законов, определяющих правовое регулирование использования отдельных роботизированных технологий, в частности, использование дронов в рамках норм Воздушного кодекса РФ.

Следует также указать на проекты модельных актов концептуального характера, которые содержат подходы к правовому регулированию соответствующих правовых явлений. Особого внимания заслуживают по крайней мере два из них. Первый - Модельная конвенция о робототехнике и искусственном интеллекте, предложенная Исследовательским центром проблем регулирования робототехники и искусственного интеллекта в 2017 г. (далее - Модельная Конвенция) $)^{10}$.

В качестве цели документа, которая обозначена разработчиками Модельной Конвенции, следует назвать, прежде всего, определение круга проблем, которые могут возникнуть в обществе и правовой системе в связи с внедрением и развитием киберфизических систем, а также обобщение основных начал робототехники о формулирование правил создания и использования роботов и искусственного интеллекта.

В рамках данного акта разработчики определили правила безопасности роботов, разработали основы создания и использования роботов, правила разработки искусственного интеллекта, призвав широкий круг специалистов для обсуждения актуальных проблем в данной области регулирования.

Второй документ - Концепция закона о робототехнике9, который представляет собой изменения в действующий Гражданский кодекс РФ в части закрепления нового правового понятия - робот-агент. Последний рассматривается, с одной стороны, как субъект права, наделенный правоспособностью, следовательно, могут принимать участие в гражданском обороте в тех видах деятельности, которые устанавливаются уполномоченным органом Российской Федерации в области робототехники.

По идее разработчиков, роботы-агенты, создаваемые для участия в гражданском обороте, подлежат включению в специальный реестр и только с этого момента могут иметь элементы правоспособности. Одновременно, робот рассматривается и как объект права, поскольку предусматривается его принадлежность собственнику или владельцу.

В документе указывается, что: "К роботам применяются общие правила об имуществе, постольку, поскольку настоящим Кодексом, законом или иными правовыми актами не установлено иное. При создании, техническом обслуживании и (или) эксплуатации роботов гражданского назначения не допускается включение в программную и (или) аппа- 
ратную часть роботов объектов, устройств и (или) функций, заведомо предназначенных для причинения вреда человеку, а также для совершения иных действий, нарушающих требования законодательства Российской Федерации". Представляется, что указанный документ, несмотря на его спорность, представляет теоретический интерес и может является основой для дискуссий.

Современные научные исследования в области робототехники и искусственного интеллекта зачастую отождествляют категории "искусственный интеллект" и "робот".

Представляется, что данные категории различны. Искусственный интеллект представляет собой информационную технологию, а робот - механизм. Однако при функционировании механизма может использоваться система искусственного интеллекта. Следовательно, механизм, в функционировании которого используется система искусственного интеллекта, может быть определен как роботизированная система искусственного интеллекта. На наш взгляд, данное понятие должно найти отражение в системе нормативноправового регулирования робототехники и искусственного интеллекта.

Представляется, что отсутствие четкого понятийного аппарата и специального регулирования затрудняет разрешение практических вопросов, связанных с использованием данных технологий на практике.

1 ГОСТ Р 43.0.5-2009. Национальный стандарт Российской Федерации. "Информационное обеспечение техники и операторской деятельности. Процессы информационно-обменные в технической деятельности. Общие положения", утвержден Приказом Ростехрегулирования от 15.12.2009 № 959-ст. Доступ из: http://www.consultant.ru/cons/cgi/online.cgi?req=doc\&ts=606638464086506 16445053736\&cacheid=CDDE3A3556825C5FFF8206AD91FD1112\&mode=splus\&base=STR\&n=13472 \&rnd $=0.8049608825822591 \# 114$ i15alhx6. Дата обращения: 01.03.2020.

2 Указ Президента РФ от 09.05.2017 № 203 "О Стратегии развития информационного общества в Российской Федерации на 2017 - 2030 годы" // Собрание законодательства РФ. 2017. N 20. Ст. 2901.

3 Указ Президента РФ от 01.12.2016 № 642 "О Стратегии научно-технологического развития Российской Федерации" // Собрание законодательства РФ. 2016. N 49.Ст. 6887.

4 Федеральный закон от 27.07.2006 N 149-Ф3 (ред. от 02.12.2019) "Об информации, информационных технологиях и о защите информации" // Собрание законодательства РФ. 2006. N 31 (1 ч.). Ст. 3448 .

5 ГОСТ ИСО 8373-2014. "Роботы и робототехнические устройства. Термины и определения" утвержден Приказом Росстандарта от 26.11.2014 N 1863-ст (утратил силу). Доступ из: $\mathrm{http}: / / \mathrm{ww}$. consultant.ru/cons/cgi/online.cgi? req =doc\&ts $=98755590405149957823188411 \&$ cacheid=B301 989FEAF1677997D802D03D8FB256\&mode=splus\&base=0TN\&n=24505\&rnd=DEDC5490B2A23F5A47 3ED80A36C2E2EE\#1hx|2oi2nib. Дата обращения: 01.03.2020.

6 Приказ Росстандарта от 01.11.2019 № 2612 "Об утверждении Программы нацио-нальной стандартизации на 2020 год". Доступ из: http://www.consultant.ru/cons/cgi/online.cgi?req=doc\&ts= 98755590405149957823188411\&cacheid=EA97F3257104B6B3D472D667D8CB54FE\&mode=splus\&bas e=LAW\&n=338715\&rnd=DEDC5490B2A23F5A473ED80A36C2E2EE\#1oer31dhxy7. Дата обращения: 01.03.2020.

7 Лаптев В.А. Понятие искусственного интеллекта и юридическая ответственность за его работу // Право. Журнал Высшей школы экономики. 2019. №2. С. 79-102.

8 Закон Южной Кореи № 9014 от 28.03.2008 года "О разработке и распространении интеллектуальных роботов". Доступ из: http://robotunion.ru/files/Robotics_SOUTH-KOREA-LAW.pdf Дата обращения: 05.03.2020. 
9 Закон Эстонии о дорожном движении от 14.07.2017 г. Доступ из: http://robopravo.ru/matierialy_dlia_skachivaniia\#ul-id-4-35. Дата обращения: 04.03.2020.

10 Незнамов А., Наумов В. Модельная конвенция о робототехнике и искусственном интеллекте. Правила создания и использования роботов и искусственного интеллекта 2017. Доступ из: http://robopravo.ru/modielnaia_konvientsiia. Дата обращения: 01.03.2020.

11 Архипов В., Наумов В. Концепция закона о робототехнике. Доступ из: http://robopravo.ru/proiekty_aktov. Дата обращения: 02.03.2020.

\title{
ROBOTIC ARTIFICIAL INTELLIGENCE TECHNOLOGIES IN THE ASPECT OF LEGAL REGULATION
}

\author{
(C) 2020 Deltsova Natalia Veacheslavovna \\ Phd in Juridical Sciences, Associate Professor \\ Samara State University of Economics \\ E-mail: natdel@mail.ru
}

Keywords: artificial intelligence, robotic system, legal regulation, information technologies.

The article is devoted to the formation of legal regulation of artificial intelligence and robot technologies in the Russian Federation. The existing regulations in this area and project legislation are considered Proposals for changing the legislation are presented.

УДК 343

Код РИНЦ 10.00.00

\section{О ПРОБЛЕМАТИКЕ ОГРАНИЧЕНИЙ, СВЯЗАННЫХ С ГОСУДАРСТВЕННОЙ ГРАЖДАНСКОЙ СЛУЖБОЙ В ТАМОЖЕННЫХ ОРГАНАХ РОССИЙСКОЙ ФЕДЕРАЦИИ}

\author{
(c) 2020 Джапарова Диана Алиевна* \\ студент \\ Самарский государственный экономический университет \\ E-mail: diana24101998@mail.ru
}

Ключевые слова: ограничения государственной гражданской службы в таможенных органах, проблематика подчиненности и подконтрольности, право на служебный рост, судимость государственного гражданского служащего таможенных органов.

Настоящая статья посвящена рассмотрению проблематики ограничения подчиненности и подконтрольности в случае наличия близкого родства/свойства государственных гражданских слуцент.

* Научный руководитель - Паулов Павел Александрович, кандидат юридических наук, до- 